\title{
Effect of disparity and viewing distance on perceived depth
}

\author{
MANFRED RITTER \\ Philipps-Universität Marburg, D-3550 Marburg/Lahn, Federal Republic of Germany
}

\begin{abstract}
It is shown that veridical depth perception presupposes the processing of both the magnitude of retinal disparity and observation distance according to a square-law function specified by the underlying geometrical stimulus relations. In the present study, after testing its existence, this constancy of depth perception was investigated by measuring perceived depth as a function of retinal disparity and observation distance. In addition, the relative effectiveness of convergence and accommodation as possible indicators of distance was examined through a conflicting-cues paradigm. It was shown that in the perception of depth the visual system computes distance by taking into account the convergence parameter only, rather than that of accommodation or of both.
\end{abstract}

This paper is concerned with three questions: (a) To what extent does the perceived depth of an object remain the same when the viewing distance varies? (b) Is perceived stereoscopic depth (with disparity kept constant) dependent on viewing distance according to a square-law relation, as expected under the assumption of complete depth constancy? (c) What is the relative effectiveness of the variables of convergence and accommodation for the determination of distance in this perceptual performance?

As an observer looks at different objects, or parts of them, located in different directions and distances, he successively fixates them and thereby radically changes their retinal representations. Nevertheless, the perceived position of the objects as well as the spatial relations among them remain approximately unchanged. This is known as the apparent constancy of space or spatial stability of visual perception. The main processes underlying this perceptual performance are as follows: (1) When an observer successively fixates object points lying in different directions, their positions are translated perceptually into an egocentric coordinate system, and thereby eliminated from observer produced stimulus movements; this results in position constancy (Bischof \& Kramer, 1968; MacKay, 1973; Matin, 1972). (2) The perceived size of objects regarded by an observer remains fairly independent of the actual observation distance (e.g., Holway \& Boring, 1941); therefore, a correction process may be assumed which "restates" the veridical object size in perception, using the information of retinal size and distance and in turn leading to size constancy (Bischof, 1966). (3) As a third type of process, depth

The author wishes to thank Professor H. W. Wendt, Macalester College, Minnesota, for his help with the English translation. constancy may be expected also to underlie the spatial stability experienced (Ono \& Cumerford, 1977). It generally means that perceived depth (i.e., a relative depth estimate of the spatial interval between two points in space) remains independent of observational distance (i.e., a spatial interval between the observer and some one point in space fixated).

Depth constancy, therefore, is expected to be involved in the following two situations: (a) when an observer looks from different viewing distances at a three-dimensional object, and (b) when an observer changes his fixation points between different objects in space and when, at the same time, the relative depth intervals between these objects are to be observed. For depth constancy, either the depth of an object itself, as in the first case, or the relative depth intervals between different objects, as in the second case, are to be represented veridically in visual perception. To reach that goal, the visual system must process information concerning depth and distance. In both cases, it is necessary to investigate to what extent depth constancy is reached and how perceived depth results from the interaction between depth and distance information. The experiments to be reported deal with only the first of the two above mentioned aspects.

\section{EXPERIMENT 1}

In normal vision, multiple sources of information about depth may be used by the visual system (e.g., motion parallax, object rotation), as well as about distance (e.g., perspective cues, interposition of objects). However, in the following, only situations are considered where one static real or stereoscopic stimulus is presented to the subject at variable distances. But even for these restricted stimulus con- 
ditions there are only a few reports dealing with the investigation of depth constancy (Foley \& Richards, 1972; Ogle, 1952; Wallach \& Zuckerman, 1963). With the exception of Wallach and Zuckerman's work (1963), the experiments reported were related to the problem of depth constancy but were not conducted to test its existence; Wallach and Zuckerman (1963), on the other hand, investigated the perception of only one physical depth interval at two different viewing distances. Therefore, using a similar experimental arrangement, the following experiment was planned to test the existence of depth constancy for different depth intervals and different viewing distances in a range of $2 \mathrm{~m}$.

\section{Method}

Subjects. The subjects were students tested first by the RodaTest (manufactured by G. Rodenstock, München; see also Guilino, 1970). All nine subjects selected had a near and far visual acuity equivalent better than $1^{\prime}$ of arc and a stereoscopic acuity equivalent better than $22.5^{\prime \prime}$ of arc.

Apparatus and Stimulation. Wire figures painted mat black and shaped like four-sided pyramids were used as stimuli. Each was supported by a shaft attached to the midpoint of one edge of the base. The pyramids were presented against a homogenous white background $\left(20 \mathrm{~cd} / \mathrm{m}^{2}\right)$ with the base always in frontal orientation and the apex pointing away from the subject. The subjects looked at the stimuli through a rectangular opening $(10 \times 15 \mathrm{~cm})$ in a mask located at a distance of $50 \mathrm{~cm}$ from their eyes.

Four pyramid-shaped stimuli were used. All had a square base with an edge of $8 \mathrm{~cm}$, but were different in the depth interval between base and apex (i.e., stimulus depth); the values presented were $3.5,6.5,9.5$, and $12.5 \mathrm{~cm}$. As a second independent variable, viewing distance was varied. The stimuli were presented at four different distances: $90,120,150$ and $180 \mathrm{~cm}$.

Procedure. The subjects were asked to give estimates of the seen depth between base and apex of the pyramid-shaped figures by producing an equal depth interval on a rod which was mounted in a constant position $20 \mathrm{~cm}$ in front of the subjects and oriented parallel to their lines of sight; the subject set the interval on the rod by adjusting a variable pointer, the position of which could be read off by the experimenter.

The subjects were randomly assigned to different random orders of the 4 by 4 conditions. Each subject was tested in all 16 conditions. In each condition, each subject made three settings; their mean was used as a measure of perceived depth. In order to get preliminary information about the intraindividual variances of the depth estimations used, the first two subjects made 10 settings each for the pyramid figures with the depth values of 3.5 and $12.5 \mathrm{~cm}$.

\section{Results}

Figure 1 shows the standard deviations (SD) for two subjects computed from the 10 settings made for two depth stimuli and four different viewing distances. A positive relation is indicated between the magnitude of stimulus depth to be estimated by the subject and the magnitude of the SD, but no such relation can be seen between viewing distance and SD. The numerical values of SD were considered to be sufficiently small to permit the reduced number of settings for the additionally tested subjects.

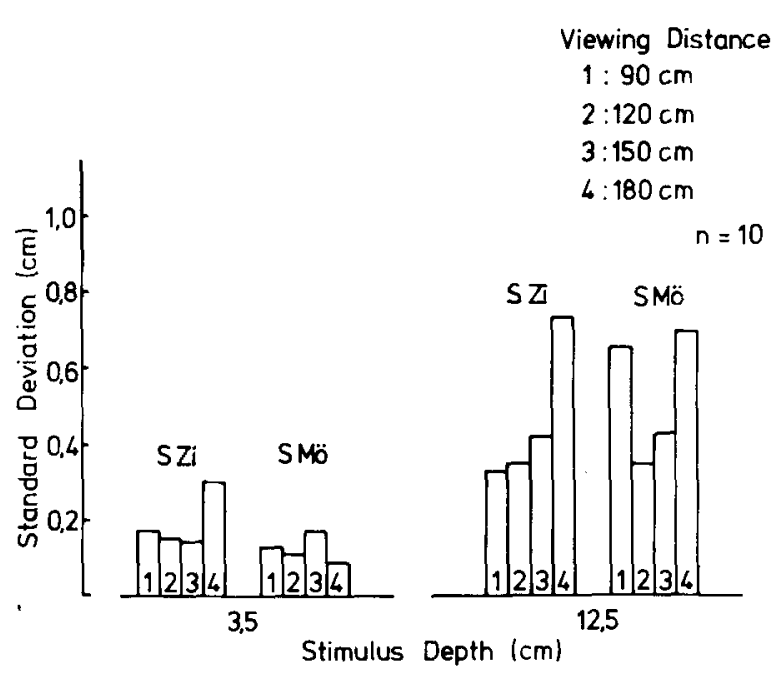

Figure 1. Standard deviations of depth estimates (cm) at two stimulus depths and four viewing distances, determined for two subjects.

In Figure 2, the magnitude of perceived depth is plotted against stimulus depth and viewing distance. For all four stimulus depths, mean perceived depth is shown to be independent of viewing distance. Accordingly, in an analysis of variance no significant $F$ values were found for Viewing Distance, $F(3,24)$ $=0.01, \mathrm{p}>.05$, or for the interaction term Viewing Distance by Stimulus Depth, $F(9,72)=0.99$, 1 .05 , but there was a highly significant $F$ value for Stimulus Depth, $F(3,24)=69.47, p<.01$. The dashed line in the figure corresponds to the values of perceived depth which would be obtained if the subject's depth perception was veridical. For the two greater stimulus depths, some minor departure from this expectation was observed, but its magnitude was not dependent on viewing distance. It cannot be

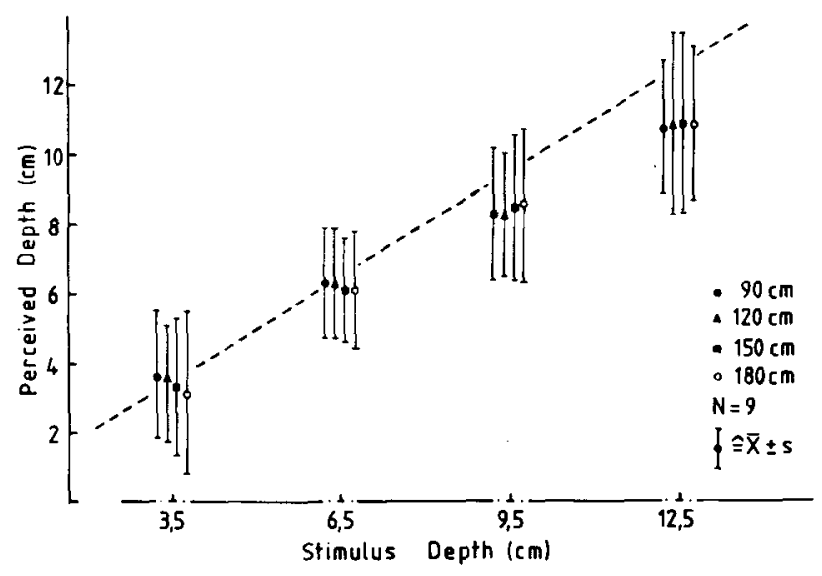

Figure 2. Perceived depth as a function of stimulus depth and viewing distance; means and standard deviations for nine subjects. The dashed line represents the values expected for complete constancy of depth. 
decided, however, if this deviation is caused by the method of measurement applied or because the subjects were unable to give veridical depth estimates for stimulus depths exceeding some degree of magnitude. The main result from this experiment is that under free viewing conditions perceived depth of stimulus objects is practically independent of variations in viewing distance, as postulated for full depth constancy.

\section{EXPERIMENT 2}

While in Experiment 1, several different cues for the depth estimate (e.g., disparity, motion parallax) might have been processed for perception, the objective of Experiment 2 was to test to what extent depth constancy would be attained in a static stimulus situation, where retinal disparity was the only cue available for depth and where accommodation and convergence were the only cues for distance.

Figure 3 a schematically shows the relation between distal and proximal stimulus variables for this case: An observer fixates, e.g., a rod with length $A B$ at $A$, and looks at it from two different distances of observation. D represents the distance between the fixation point and the eyes of the observer, $d$ the physical depth of the seen rod, and $i$ the interocular distance. It will be observed that the physical depth, $\mathrm{d}$, is imaged onto the the retinas as an angular difference, $\gamma_{1}-\gamma_{2}$, and that this difference is a measure
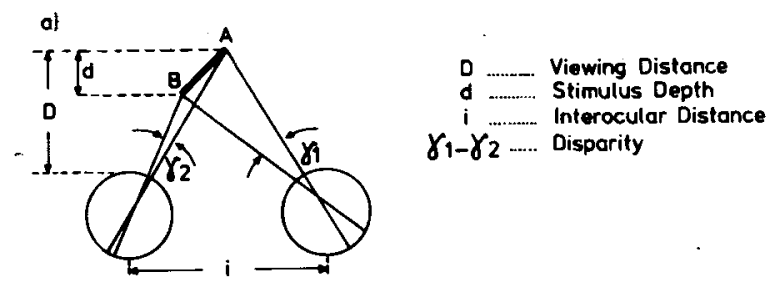

b)
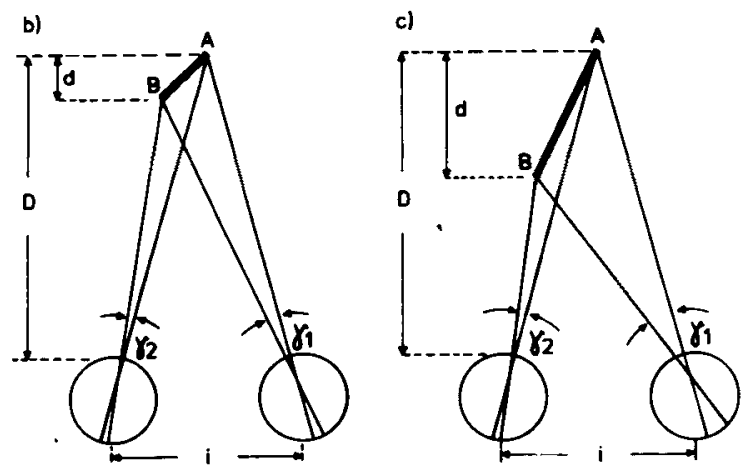

Figure 3. Illustration of the relation between stimulus depth, $d$, viewing distance, $D$, interocular distance, $i$, and retinal disparity, $\gamma_{1}-\gamma_{2}$. A comparison of (a) and (b) shows the effect of two different magnitudes of $D$; a comparison of (a) and (c) shows to what extent $d$ must be larger for retinal disparity to remain constant. of the magnitude of the retinal disparity. A comparison of Figures $3 \mathrm{a}$ and $3 \mathrm{~b}$ demonstrates that the magnitude of the retinal disparity corresponding to some constant stimulus depth, $d$, is much smaller for the larger of the viewing distances; Figure $3 \mathrm{a}$ and $3 \mathrm{c}$ show that in order to keep disparity constant one has to choose a much greater stimulus depth for the larger viewing distance.

In the case where $D$ is very large relative to $d$, and $B$ is not too far from the perpendicular of $i$ on which $A$ is located, the relation among the variables, respectively, of stimulus depth $d$, viewing distance $D$, interocular distance $i$, and retinal disparity, $\gamma_{1}-$ $\gamma_{2}$, can be formulated as

$$
\gamma_{1}-\gamma_{2}=\frac{i \cdot d}{D^{2}}(\mathrm{rad})
$$

(for a detailed discussion, see Graham, 1951). This equation states that the magnitude of disparity is proportional to the product of stimulus depth and the interocular distance and is inversely proportional to the square of the observation distance. When $d$ is held constant for a given observer, then the retinal disparity decreases with an increase of viewing distance according to an inverse square law. (For adults, interocular distances are considered to be constant and therefore can be disregarded in the following analysis.)

If complete depth constancy is to be achieved in perception, the decrease of retinal disparity as a function of viewing distance has to be internally cancelled by means of some kind of compensation process (Bischof, 1966). If perceived depth is to correspond to stimulus depth, then the magnitude of retinal disparity attributable to d must be "multiplied" by a value corresponding to the square of viewing distance and must be related to the interocular distance of the observer. The degree of depth constancy actually attained will thus be dependent on the processing of information about object depth and observation distance.

Therefore, the following experiment was designed to test the relation between disparity, viewing distance, and perceived depth as formulated above. The objective was to investigate whether perceived depth is a quadratic function of observation distance under conditions where retinal disparity is held constant. This was to be expected from initial experimental evidence on depth constancy (Wallach \& Zuckerman, 1963) and from the results of Experiment 1 . On the other hand, Foley (1967) showed that a linear depth-distance relation rather than the quadratic one suggested above was in better agreement with his results. He was, however, working with relatively large disparities, which possibly lie outside the range of the so-called "patent stereopsis" (Foley 
\& Richards, 1972). In the following experiment, the magnitude of disparity employed was clearly small enough to lie within the range where depth has been shown to increase monotonically with disparity (Lawson \& Gulick, 1967; Ogle, 1952; Richards, 1971).

\section{Method}

Subjects. All eight subjects were students having normal acuity and stereoscopic vision as tested by the Roda-Test (see Experiment 1).

Apparatus and Stimulation. The subjects looked at a translucent screen through a system of Polaroid filters, a beam splitting mirror, and a rectangular opening in a mask, as shown in Figure 4. Pyramid-shaped wire figures also were used as stimuli, their square bases adjacent to the rear of the screen. The outline shadow of one of these figures was cast onto the screen by means of two projector lamps in front of which a second pair of Polaroids was mounted. The projection of the stimuli was stereoscopic; only one of the two shadows was visible to one eye. The luminance of the screen (as measured through the Polaroids) was $50 \mathrm{~cd} / \mathrm{m}^{2}$. By means of a beam splitter, a probe consisting of a small circular luminous disk was superimposed on the stimulus field; along with the pyramid, the subject saw the luminous disk $2 \mathrm{~cm}$ above. The probe could be moved by the experimenter on a path perpendicular to the direction of the subject's line of sight. By thus manipulating the probe, the distance could be varied at which the subject would perceive it. The position of the probe finally reached could be read off in millimeters.

The independent variable of interest was viewing distance; four values of stimulus distance were examined: $90,120,150$, and $180 \mathrm{~cm}$. In all conditions, the retinal size and disparity of the outline stereograms were held constant, using $2^{\circ} 32^{\prime}$ of are as the fixed length of the pyramids' bases and $4^{\prime} 20^{\prime \prime}$ of arc as the magnitude of disparity (corresponding to the stimulus depth between base and apex). This was accomplished by using different wire configurations and appropriate projection distances. The values of size and disparity used here corresponded approximately to those of a real wire pyramid with a base of $8 \times 8 \mathrm{~cm}$ and a height (or depth, here) of $6.5 \mathrm{~cm}$ and presented to subject at a distance of $180 \mathrm{~cm}$.

Procedure. Pyramid and probe were simultaneously presented. The subject's task was to let the experimenter manipulate the probe until it corresponded exactly either with the perceived depth of the base or with the apex of the pyramid, depending on

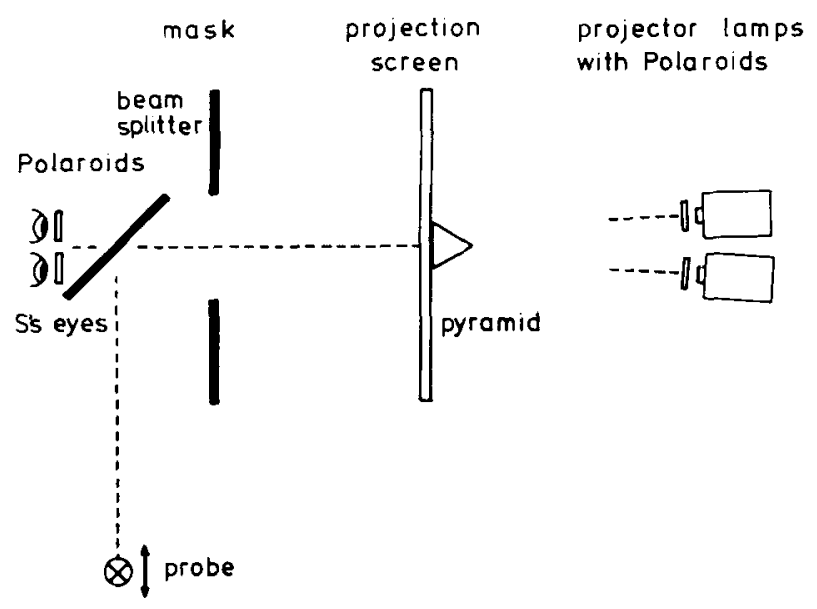

Figure 4. Schematic diagram of the apparatus. instructions. The difference between these two positions of the probe was used as a measure of perceived depth.

In applying this method of measurement, it was assumed that it is a valid indicator of perceived distance. In order to check this assumption, the following experiment was performed. The relation between stimulus and perceived distance was examined by varying stimulus distance over a range of values of $90,120,150$, and $180 \mathrm{~cm}$. Two students served as subjects. Stimulus presentation in this case was not stereoscopic, and the same outline shadow of a pyramid was presented to both eyes. The experimenter adjusted the probe until stimulus and probe appeared to lie in an identical plane. Under each condition, eight settings were used.

In the main experiment, each subject went through a reduced number of four settings for the base and four for the apex of the pyramid for each condition. The mean difference between the two settings was used as a measure of perceived depth. The order of presentation employed for the conditions was varied across subjects.

\section{Results}

Figure 5 shows the results obtained in testing the method of depth measurement described above. Means and standard deviations for two subjects are given. A linear relationship between physical and perceived distance was obtained, as would be required for this method to be applicable to depth measurement. The standard deviations were sufficiently small to permit a reduced number of settings in the experiments following.

As the main result, Figure 6 shows the relationship between stimulus distance and perceived depth for a constant value of retinal disparity. The dashed line corresponds to the values that would be expected if complete constancy of depth were, in fact, achieved by the visual system. (For the calculation of this function, the eye's center of rotation was taken as reference point and an interocular distance of $64 \mathrm{~mm}$ was assumed.) The observed values of perceived depth were in good agreement with the values expected; individual comparisons of means showed none of the $t$ values to be statistically significant. (In order, the $t$ values for the four viewing distances from 90 to $180 \mathrm{~cm}$ were: $\mathrm{t}(7)=0.18, \mathrm{t}(7)=0.01$, $t(7)=0.53, t(7)=1.18$; for all, $p>.05)$. The quadratic increase of perceived depth with a linear increase of observation distance, with disparity held constant, indicates that complete depth constancy was achieved also in those situations of limited depth and distance information that were used in this study. Apparently, the relation observed here between depth and distance can only result if visual depth is computed from both retinal disparity and observational distance.

\section{EXPERIMENT 3}

In the conditions realized in Experiment 2, two possible indicators remained which might be used by the visual system to determine target distances, 


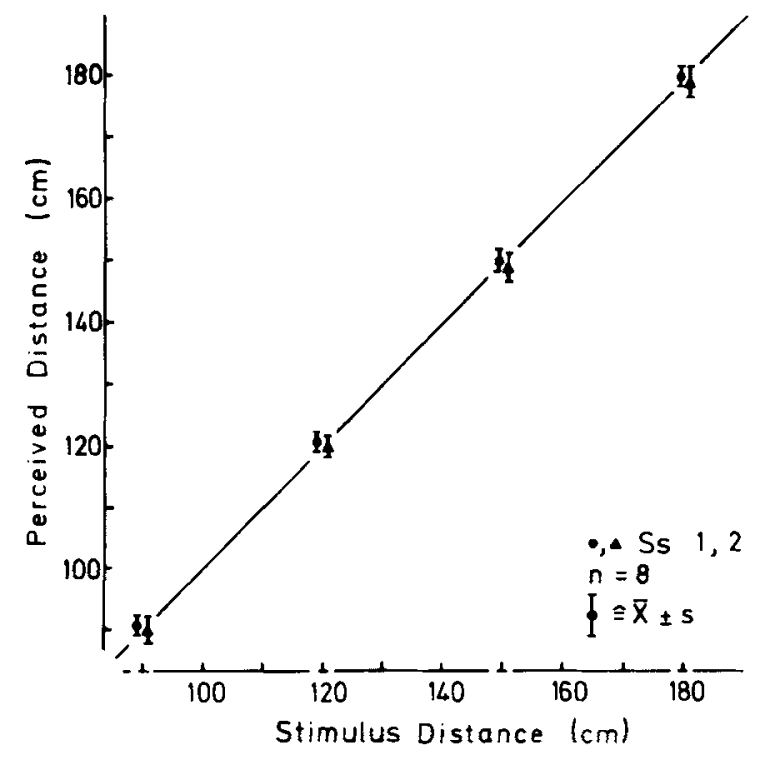

Figure 5. Perceived distance as a function of stimulus distance; means and standard deviations for two subjects.

viz., convergence and accommodation. For both variables, distance judgments can, in fact, be based on them (cf. Heun, 1968; Künnapas, 1968; Owens \& Leibowitz, 1976; von Hofsten, Note 1); moreover, they are being used for the determination of distance in size constancy (cf. Heineman, Tulving, \& Nachmias, 1959; von Holst, 1955). Such evidence is more substantial and convincing, however, for the variable of convergence.

There is some similarity between size and depth constancy, insofar as, in both cases, perceptual estimates are to be given by an observer while viewing distance varies; therefore, it could be expected

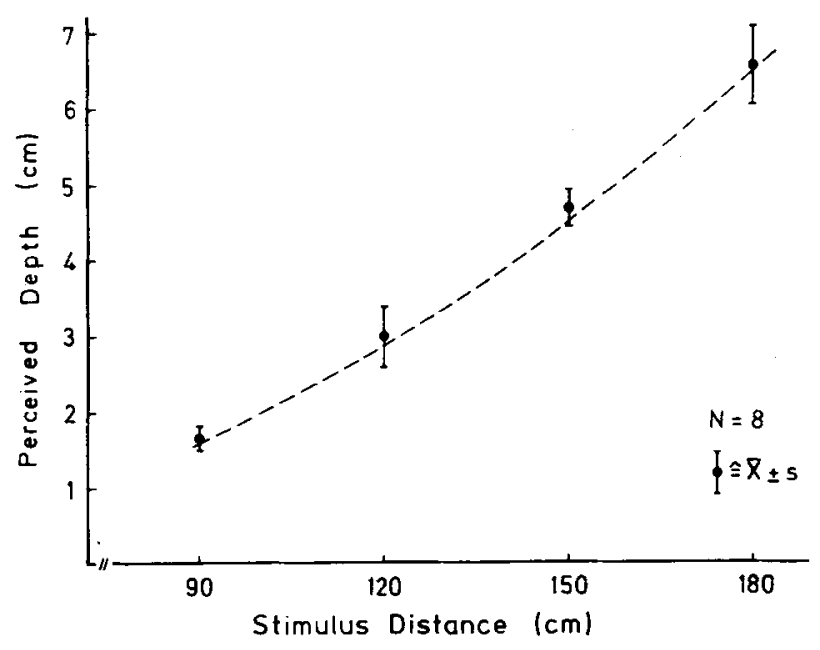

Figure 6. Perceived depth as a function of viewing distance with disparity kept constant; means and standard deviations of eight subjects. The dashed line represents the values expected for complete constancy of depth. that also in depth constancy both variables, convergence and accommodation, might contribute to the distance determination. By applying a conflicting-cues paradigm, the following experiment was designed to examine whether one of the variables alone, or both together, here utilized by the visual system in the perception of depth.

Based on the results of Experiment 2 for depth constancy, a systematic correction process may be assumed. By means of this mechanism and for a constant stimulus depth, the increase or decrease of retinal disparity normally produced by changing the target distance is perceptually compensated by using a squared magnitude corresponding to viewing distance. This, in turn, presupposes that the actual distance can be validly measured by the visual system and that the resulting magnitude can serve as a basis for an adjusting signal. In cases where two or more variables are capable of giving information about the same physical attribute, e.g., as in the perception of distance, questions arise as to how these different values are combined to form a single unique adjustment value. It is possible to distinguish, primarily, two classes of possible interactions among such variables: (a) The perceptual system takes account of only one of the values available while disregarding the others ("alternative solution"; Bischof, 1974, p. 178), or (b) it computes some average, weighting the several values with the same or with different coefficients ("compromise solution"; Bischof, 1974, p. 178).

For the situation considered here, the question was whether distance determination in depth perception is based on one of the values, convergence or accommodation (alternative solution), or on some average of both (compromise solution). Therefore, perception of depth was investigated (1) in a "noconflict" condition, where accommodation and convergence corresponded to identical distance values, as well as (2) in a "conflict" condition, where the values of the two variables would correspond to contradictory values of observation distance (Fry, 1937). In Condition 1, perceived depth was determined for two values of distance. In Condition 2, a special experimental arrangement was introduced: subjects were forced to fixate the stereoscopic stimuli with an angle of convergence corresponding to one of the distance values in the no-conflict situation, while at the same time the requirement for accommodation corresponded to the other distance value used in the no-conflict condition. If cue dominance is relevant, as in the case of alternative solutions, then it would be expected that the magnitude of perceived depth in the conflict condition would agree with one of the two values in the no-conflict condition-which one, of course, depending on whether accommodation or convergence was dominant. On the other hand, if the compromise solution is relevant, then it would be 
expected that the perceived depth would assume a value between the two values observed in the noconflict condition.

\section{Method}

Subjects. All seven subjects were students having normal visual acuity and stereoscopic vision as tested by the Roda-Test (see Experiment 1).

Apparatus and Stimulation. The experimental arrangement was the same as in Experiment 2. Random-dot matrices ( 60 by 60 ) were used as stereoscopic stimuli. Depending on the direction of disparity, the subject would see a square center section either in front of or behind a larger reference square. The center square subtended $2^{\circ}$ of arc, the reference square $5.7^{\circ}$. Disparity was set at the two values of $8^{\prime}$ and $16^{\prime}$ of arc, respectively, and in two directions, "crossed" (center in front of the reference square) and "uncrossed" (center behind the reference square), respectively.

In the no-conflict condition, observation distances of 90 and $150 \mathrm{~cm}$ were used. In the conflict condition, the screen was placed at $150 \mathrm{~cm}$ and the centers of the stereograms were laterally separated by $4.2 \mathrm{~cm}$. In order to maintain clear single vision, the eyes had to converge; in this case, the proper convergence angle corresponded to a target distance of $90 \mathrm{~cm}$ in normal vision. In other words, accommodation remained fixed to a distance of $150 \mathrm{~cm}$, while convergence corresponded to $90 \mathrm{~cm}$. The two target squares were no longer seen in the plane of the projection screen, as in the no-conflict condition, but appeared at approximately the intersection of the subjects' lines of sight.

Procedure Perceived depth was measured using the method of Experiment 2. Each subject was examined under both directions and magnitudes of disparity presented at two distance values in the no-conflict situation, as well as the 2 by 2 conditions in the conflict situation. Four subjects were tested first in the no-conflict situation, and the other three were tested first in the conflict situation. In each of these situations, the disparity conditions were presented in random order, each subject using a different order. In each condition and for each subject, measurements were repeated four times; the mean was used as the final value for calculations.

\section{Results}

Figure 7 shows the means and standard deviations obtained in the no-conflict situation. As anticipated on the basis of the results of Experiment 2, perceived depth was found to be nonlinearly related to target distance. Perceived depth was again dependent on both retinal disparity and observational distance. There were no specific effects attributable to crossed and uncrossed disparities. In an analysis of variance, highly significant $F$ values were found for the factors of Viewing Distance, $F(1,6)=204.7, p<.005$, and Magnitude of Disparity, $F(1,6)=999.7, p<.005$, and for the interaction between them, $F(1,6)=107.6$, $\mathrm{p}<.005$. Neither Direction of Disparity nor any of the interactions involving it was significant.

To answer the question of Experiment 3, the results of the no-conflict situation have to be compared with those of the conflict situation. Figure 8 presents the appropriate means and standard deviations. The values obtained for the observation distance of $90 \mathrm{~cm}$ in the no-conflict condition are also shown. No statistically significant differences could be demonstrated for the depth-distance relation between the conflict situation $(90 / 150 \mathrm{~cm})$ and

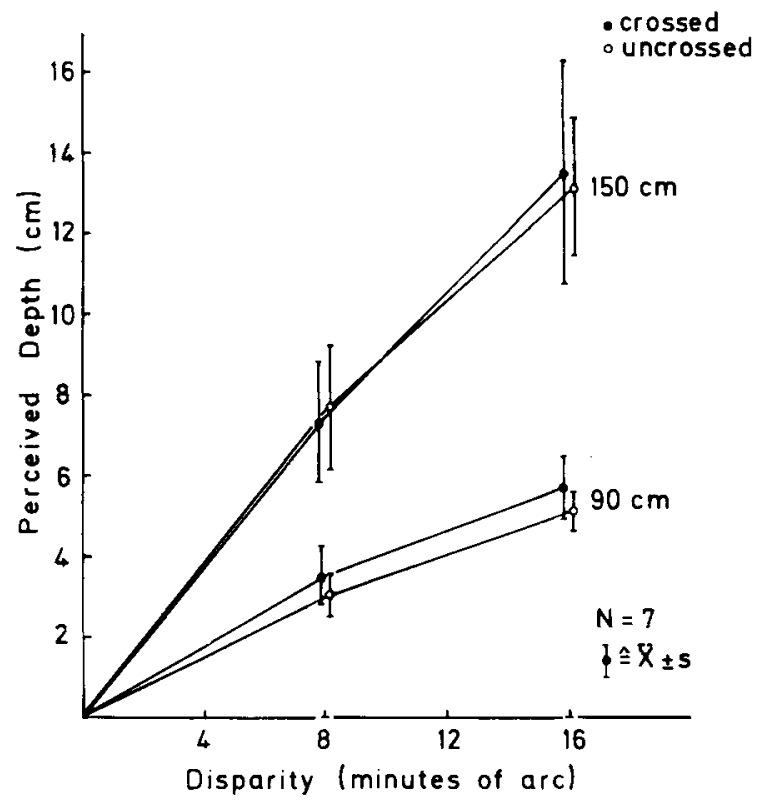

Figure 7. Perceived depth as a function of disparity shown for two distance values, and crossed and uncrossed disparities; means and standard deviations of seven subjects.

the 90-cm-distance condition of the no-conflict situation $(90 / 90 \mathrm{~cm})$. (The analysis of variance indicated only an effect of Magnitude of Disparity, $F(1,6)=$ $274.7, p<.005$; for all other main effects and interaction terms, $p>$.05.) In the conflict situation, perceived depth, therefore, was evidently determined solely by the magnitude of disparity and by that value of distance at which convergence was fixed. Accommodation, which was simultaneously set at a different distance, showed no observable effect on perceived depth. This result is consistent with the hypothesis of an alternative solution specifically based upon the convergence parameter.

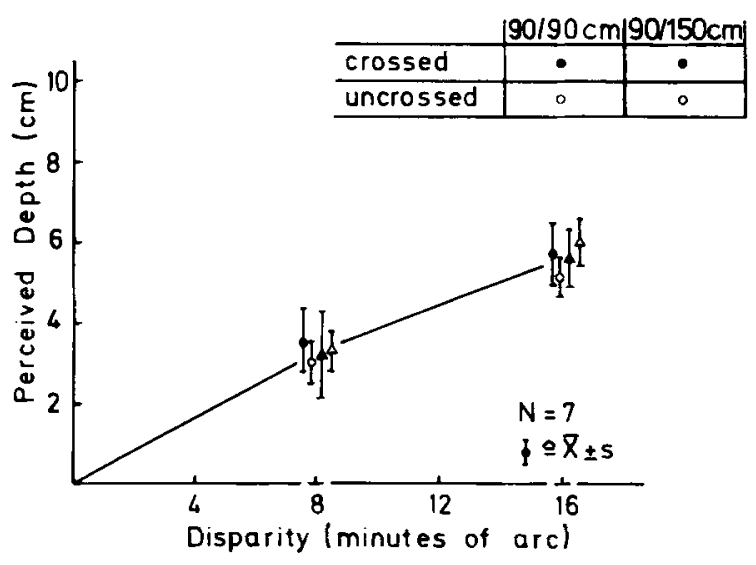

Figure 8. Perceived depth as a function of disparity for the no-conflict condition $(90 / 90 \mathrm{~cm})$, the conflict condition $(90 /$ $150 \mathrm{~cm}$ ), and crossed and uncrossed disparities; means and standard deviations of seven subjects. 


\section{DISCUSSION}

After testing its existence (Experiment 1), depth constancy was investigated in a situation of reduced depth and distance information (Experiment 2). It was concluded that complete depth constancy was obtained; this could be shown from the comparison of the expected and observed relationships between perceived depth and viewing observation distance when retinal disparity was kept constant: Perceived depth was related to observation distance according to a quadratic function, leading to the interpretation that the visual system "computes" perceived depth by taking into account both retinal disparity and observation distance. Experiment 3 demonstrated that in the particular stimulus situation examined the visual system utilized convergence as an indicator of distance, disregarding accommodation cues.

The first result agrees with the assumption that visual space perception not only incorporates constancy of position and size but also constancy of depth. In this respect, the present study further validates the work of Wallach and Zuckerman (1963); in addition, it is consistent with other previous studies (e.g., Gilinsky, 1951; Mayer-Hillebrand, 1932) - at least in the range of viewing distances tested-where the relation between physical and perceived distance was determined through the use of scaling methods. On the other hand, the square-law relationship between perceived depth and distance obtained in Experiment 1 disagrees with the results of Foley (1967) in which a linear relationship is stated. This disagreement can only be resolved by further experiments; it seems likely that it is caused by differences in stimulus conditions and specific aspects of experimental procedure. The quadratic relation, however, is expected if space perception is to be veridical; this objective can be realized only if disparity values are transformed according to a quadratic and not to a linear distance function. Thus, it would seem indicated that any theory of stereopsis should include not only the explanation of the disparity-depth relation, but also the recalibration of this relation in its dependence upon observation distance. Present theories meet this requirement in part only (Dodwell, 1970; Julesz, 1971; Sperling, 1970).

Furthermore, it should be noted that in the present study the relation among disparity, distance, and perceived depth was examined for adult subjects whose interocular distances could be considered constant. During the course of development, interocular distance becomes larger, and this increase must be expected to impose consequences on the visual processing of depth. If, for example, an adult observer with an interocular distance of $65 \mathrm{~mm}$ and a 9-year-old child with an interocular distance of
$56 \mathrm{~mm}$ (Trendelenburg, 1961 , p. 311) look at an object with a depth of $10 \mathrm{~cm}$ from a viewing distance of $2 \mathrm{~m}$, then the magnitude of disparity for the adult equals $5^{\prime} 35^{\prime \prime}$ of arc, and for the child 4' $39^{\prime \prime}$ of arc. Therefore, it is a rather complicated problem to explain the ontogeny of depth constancy. The organism not only has to develop a single appropriate function which can compensate the proximal stimulus for the varying observation distance, but also is forced continually to adjust this function in order to cope with the changing interocular distance throughout development. If binocular stimulation specifies veridical properties of space, this can only result from a continuous process of calibration.

It has already been shown that the functional meaning of the variables involved can be changed. Shlaer (1971), for example, has demonstrated that in kittens which were exposed to an artificially altered visual environment by wearing prisms in front of the eyes, the distribution of disparities in a sample of cortical cells was shifted in a direction which would tend to compensate for the stimulus changes introduced. This clearly indicates that the neural processing of disparity is not based upon a fixed relation between physical depth and disparity but can adapt to specific environmental changes. Similar procedures can change the structure of the visual cortex in adult animals as well, as shown by Creutzfeldt and Heggelund (1975). In experiments on human adaptation, comparable to those performed by Held and his co-workers on sensory-motor coordination, it was observed that subjects, while wearing prismatic squint glasses, underestimate perceived distance at the beginning of the experiment and regain increasingly normal perception of distance during the adaptation process (Ischebeck, 1966; Wallach, Frey, \& Bode, 1972). Based on such results, we would suggest that the relation among disparity, interocular distance, observation distance, and perceived depth is calibrated by active reaching movements and/or active locomotion in the environment in order to achieve full depth constancy. The stability of space perception will thus be dependent on this adaptation process.

The second result of the present study has stressed the importance of the variable of convergence for the determination of distance in stereopsis; accommodation does not carry any weight as an indicator of this type, as revealed by Experiment 3. This seems somewhat different from the situation of size constancy where changes in accommodation alone can bring about small, but significant, corrections of size (Heineman et al., 1959). But, in the case of depth perception, it seems plausible that accommodation is not included in the determination of distance. Depth perception as analyzed here presupposes binocular vision; i.e., the visual system would always be cap- 
able of utilizing the convergence variable to determine target distance and therefore can dispense with the accommodation variable, which, in fact, has not been shown to be a valid cue for the perception of distance (Hochberg, 1972).

\section{REFERENCE NOTE}

1. Hofsten, C. von. The role of convergence in visual space perception. Report 168, Department of Psychology, University of Uppsala. 1974.

\section{REFERENCES}

Bischof, N. Psychophysik der Raumwahrnehmung. In W. Metzger (Ed.), Handbuch der Psychologie, Allgemeine Psychologie, Wahrnehmung und Bewusstsein (Vol. 1/1). Gottingen: Hogrefe Verlag 1966.

Bischоғ, N. Optic-vestibular orientation to the vertical. In H. H. Kornhuber (Ed.), Handbook of sensory physiology. Vestibular system. Part 2: Psychophysics, applied aspects and general interpretations (Vol, VI/2). Berlin, Heidelberg, New York: Springer Verlag, 1974.

Bischof, N., \& KRAmer. E. Untersuchungen und Überlegungen zur Richtungswahrnehmung bei willkürlichen sakkadischen Augenbewegungen. Psychologische Forschung, 1968, 32, 185-218.

CReutzfeldt, O. D., \& Heggelund, P. Neural plasticity in visual cortex of adult cats after exposure to visual pattern. Science, 1975, 188, 1025-1027.

Dodwell. P. C. Visual pattern recognition. New York: Holt, Rinehart. \& Winston, 1970.

Foley. J. M. Binocular disparity and perceived relative distance: An examination of two hypotheses. Vision Research, 1967, 7, 655-670.

Foley, J. M.. \& RichaRds, W. Effects of voluntary eye movement and convergence on the binocular appreciation of depth. Perception \& Psychophysics, 1972, 11, 423-427.

FrY, G. A. An experimental analysis of the accommodation-convergence relation. American Journal of Optometry, 1937, 14. 402-414.

Gilinsky, A. Perceived size and distance in visual space. Psychological Review', 1951, 58, 460-482.

Graham, C. H. Visual perception. In S. S. Stevens (Ed.), Handbook of experimental psychology. New York: Wiley, 1951.

Guilıno, G. Sehtest für den Arbeitsplatz. Arbeitsmedizin, Sozialmedizin, Arbeitshygiene, 1970, 5, 100-104.

Heineman, E. G., Tulving, E., \& Nachmias, J. The effect of oculomotor adjustments on apparent size. American Journal of Psychology. 1959, 72, 32-45.

Heun. B. Die visuell-motorische Koordination bei der egozentrischen Tiefenlokalisation im Dunkelraum. Unpublished thesis, Institut für Psychologie, Universität Marburg, 1968.
HochberG, J. Perception (II): Space and movement. In J. W. Kling \& L. A. Riggs (Eds.), Woodworth \& Schlosberg s experimental psychology. London: Methuen, 1972.

Holst. E. von. Die Beteiligung von Konvergenz und Akkommodation an der wahrgenommenen Grössenkonstanz. Naturwissenschaften, 1955, 42, 444-445.

Holway, A. H., \& Boring, E. G. Determinants of apparent visual size with distances variant. American Journal of Psychology, $1941,54,21-37$.

IsCHEBECK, L. Visuell-motorische Koordination bei absoluter Tiefenlokalisation. Unpublished thesis, Institut für Psychologie, Universität Marburg, 1966.

Julesz. G. Foundations of Cyclopean perception. Chicago, London: University of Chicago Press, 1971.

KÜNNAPAS, T. Distance perception as a function of available visual cues. Journal of Experimental Psychology, 1968, 77, 523-529.

Lawson, R. B..\& Gulick, W. L. Stereopsis and anomalous contour. Vision Research, 1967, 7, 271-297.

MACKAY, D. M. Visual stability and voluntary eye movements. In R. Jung (Ed.), Handbook of sensory physiology. Central processing of visual information, Part $A$ (Vol. VIl/3). Berlin, Heidelberg, New York: Springer-Verlag, 1973. Pp. 307-331.

Matin, L. Eye movements and perceived visual direction. In D. Jameson \& L. M. Hurvich (Eds.), Handbook of sensory physiol. ogy. Visual psychophysics (Vol. VII/4). Berlin, Heidelberg, New York: Springer-Verlag, 1972. Pp. 331-380.

Mayer-Hillebrand, F. Über die scheinbare Entfernung oder Sehtiefe. Zeitschrift für Sinnesphysiologie, 1932, 63, 38-85.

OGLE, K. N. On the limits of stereoscopic vision. Joumal of Experimental Psychology, 1952, 44, 253-259.

ONo, H., \& Cumerford, J. Stereoscopic depth constancy. In W. Epstein (Ed.), Stability and constancy in visual perception: Mechanisms and processes. New York: Wiley, 1977.

OWENS. D. A., \& LeibowrTz, H. W. Oculomotor adjustments in darkness and the specific distance tendency. Perception \& Psychophysics, 1976, 20, 2-9.

RICHARDS. W. Size-distance transformations. In O. J. Grüsser \& R. Klinke (Eds.), Zeichenerkennung durch biologische und technische Systeme. Berlin, Heidelberg, New York: Springer Verlag, 1971.

SHLAER, R. Shift in binocular disparity causes compensatory change in the cortical structure of kittens. Science, 1971, 173, 638-641.

SPERling, G. Binocular vision: A physical and neural theory. American Journal of Psychology, 1970, 83, 461-534.

Trendelenburg, W. Der Gesichtssinn (2nd ed.). Berlin, Göttingen, Heidelberg: Springer, 1961.

W Allach, H., FrEY, K. J., \& Bode, K. A. The nature of adaptation in distance perception based on oculomotor cues. Perception \& Psychophysics, 1972, 11, 110-116.

W AllaCh, H., \& ZuCKerman, C. The constancy of stereoscopic depth. American Journal of Psychology, 1963, 76, 404-412.

(Received for publication February 14, 1977; revision accepted June 7,1977 .) 